\title{
Climate Change Action - What are the gaps in capacity building which is making implementation fail ?
}

\section{Policies meant not mere for negatiations but for aligning, applying and implementing}

Dr. Prachi Ugle Pimpalkhute,

ESDW2021- ESDW European Wide Initiative Organizer, Lead and Mentor for Mission

De Facto Cities and Communities and Founder and Climate Change Crusader

Eco Endeavourers Network

IUCN Union Member Commission Environmental Management

SPP Sustainable Procurement Ambassador,

UN SDG Ambassador,

ACT 4 SDGs

Ambassador,

Association of Commonwealth Universities Higher Education and the SDGs Network

Member

UN Partnership for SDGs Platform Member

\section{Bespoke on What Climate Change Action Means.....?}

In the recently concluded Conference of Parties (COP26) Glasgow, UK Summit 2021 the key issues focused on the 1.5 degrees Paris Agreement implementation, NDCs updating by countries, adaptation, lack of financial machinery uniformly amidst countries, mitigation and loss and damage, science based targets and nature based targets. Another mentioning was on mobilization and capacity building, which is the main attribute for climate change action failing in implementation. As per the UNFCCC capacity building portal, priority areas by activities for capacity building to channelize for getting tangible and actionable implementation at base level and to forefront include the following pointers as notings to know, upscale, upgrade and implement (the data set year range from 1975 -2021, till date):

- Institutional capacity building, including the strengthening or establishment, as appropriate, of national Climate change secretariat or national focal points. 288 (11.4\%)

- Enhancement and /or creation of an enabling environment. 193 (7.6\%)

- National Communications. 72 (2.8\%)

- National Climate Change Programmes. 95 (3.8\%)

- Greenhouse gases inventories, emission data base management and systems for collecting, managing and utilizing activity data and emission factors. 142 (5.6\%)

- Vulnerability and adaptation assessment. 92 (3.6\%)

- Capacity building for implementation of adaptation measures. 263 (10.3\%)

- Assessment for implementation of mitigation options. 239 (9.4\%) 
- Research and systematic observation, including meteorological, hydrological and climatological services. 152 (6.2\%)

- Development and transfer of technology. 144 (4.7\%)

- Improved decision making, including assistance for participation in international negotiations. 147 (5.8\%)

- Clean Development Mechanism. 107 (4.2)

- Needs arising out of the implementation of Article 4, Paragraph 8 and 9 of the convention. $45(1.8 \%)$

- Education, training and public awareness.434 (7.1\%)

- Information and networking including the establishment of databases. 118 (4.7\%)

This paper uses interactive map of the UNFCCC to know the priority areas and gaps about which countries need to focus on climate change action at implementation level. Climate change action needs stakeholder connect to get the targets fruitified into action.
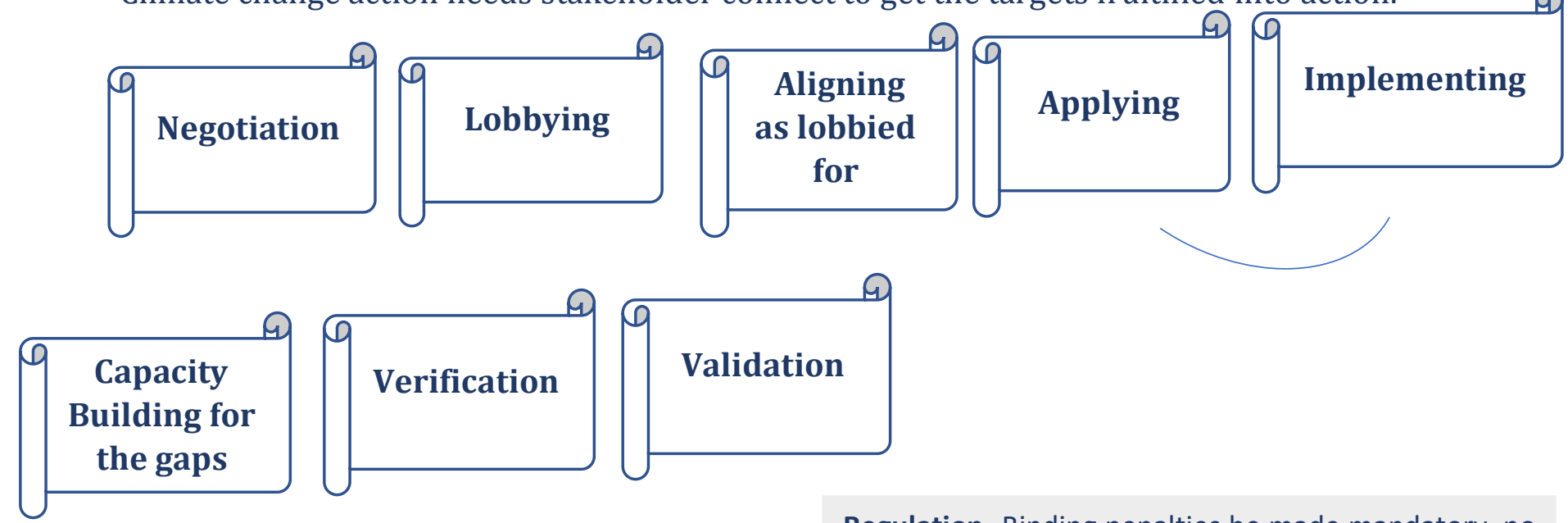

Regulation- Binding penalties be made mandatory, no voluntary commitments and submissions, levy tax,

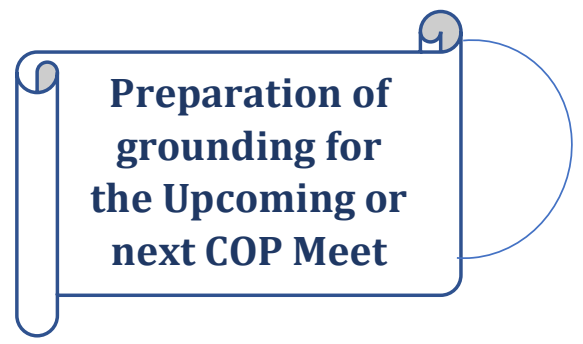
withdrawal from the listed parties of Conference and G20, G7, BRICS Nations, sharing of outcomes in a common and uniform registry. Regulatory machinery with stringent legalized applicables will ease facilitation and implementation and shall get targets achieved.

Submission of targets achieved much before negotiations begin in the registry, shall strengthen bargaining or lobbying attribute as no country can be binded with other country targets. Regulation + country specific targets and then table down for negotiation. Need to be vocal as regard to carbon markets per se and in order to avoid double counting, as it is biggest road block for climate change action. 


\section{Climate Change Action Core Competencies Capacity Building from Gaps to Rebound - What, which and where gaps are percolating in and can we rebound it ?}

What : Dependency on Parties to the COP and admitted organizations with observer status, for knowledge transfer, capacity building and outreach to the developing countries including vulnerable, marginalised, small island nations and least developing nations. Lack of uniform applicability.

Which : Pursuant to decision 16/CP.22, paragraph 9, United Nations agencies, multilateral organizations and relevant admitted observer organizations engaged in providing capacitybuilding support to developing countries are invited to submit information to be uploaded onto the capacity-building portal. Non-Party stakeholders need to request a login by email and then submit the information by clicking onto the submit link to account.

\section{Lack of self competencies or expertise, undue dependencies.}

Where : In entity level supply chain, management and board, country level, regional and local level specificities, infrastructure level, policy level, implementation level, adaptation and mitigation measures level, decision making level, validation level and insufficient and lack of competent institutional capacities and capabilities, cross sectoral confusion as regard to emission reduction commitments. Irregularities at country, regional and local level in outreach of climate change action.

Why agencies and organizations submit capacity building processes when countries as a whole can report ?: They should be submitted or outreached into action as a cumulative action and not at individual or agency level capacity building process as it does not reflect outcomes and targets uniformly .

Who does it? Monitoring and reviewing the capacity building framework :

The Subsidiary Body for Implementation (SBI), regularly monitors and reviews progress on the implementation of the frameworks for capacity-building in developing countries and countries with economies in transition (EITs), contained in decisions 2/CP.7 and 3/CP.7, and forwards draft decisions to the Conference of the Parties (COP) and the Conference of the Parties serving as the meeting of Parties to the Kyoto Protocol (CMP), as per the Paris Agreement, Durham forum for their consideration and adoption, as appropriate. The reviews involve a variety of actors. Parties report on progress they have made on capacity-building activities in their national communications submitted to the UNFCCC secretariat. The Global Environment Facility (GEF) and United Nations agencies also submit information to the secretariat on capacity-building.

The Durban Forum on capacity-building was acknowledged as a key modality that has enhanced progress in implementing the framework. In addition, the value of the capacitybuilding work of constituted bodies under the Convention as well as of strengthening the participation of other stakeholders, including non-State actors, in capacity-building activities, was noted. While the importance of sharing examples of best practice and lessons learned, and building long-term capacity in developing countries was highlighted, it was also 
noted that monitoring and reviewing the impacts of capacity-building remains challenging and needs to be conducted in specific contexts.

Invited Annex II Parties along with bilateral, multilateral and private sector agencies continue to provide financial support for the implementation of the capacity-building framework, including the recent development of terms of reference and adoption of term of reference. Recognizes that significant progress has been made in building the capacity of EITs (economies in transition), and some EITs have started to share their own expertise, knowledge and lessons learned on capacity-building with Non-Annex I Parties.

Why are capacity building initiatives not mapped as per stakeholders, why it is vice versa?

As regard to reporting or disclosure for Sustainability, why are not NDCs, Science Based Targets, Nature Based Solutions, The task force for Climate Related Financial Disclosure (TCFD) mapped as per stakeholder. Not one fits for all, so why create competencies in those stakeholders who do not fall in preview of it, is a superlative statement, as every stakeholder can upscale the initiatives as per their requirement and be a cohort in climate change action.

\section{The Real Nudge : From Solutions to Breakthrough and Issues to Opportunities - Will it rebound or relapse?}

Why orient the capacities as per problem ? Solutions shall be visible and viable for breakthrough -

- Problem based learning, upskilling, upscaling and implementation - Climate Change Action Learners, Climate Change Action Crusaders, Climate Change Action Ambassadors, Climate Change Action Facilitators, Climate Change Action Implementers, Climate Change Action Regulators, Climate Change Practitioners. (Every country across all levels, sections, sectors and beyond the scope of boundaries should have this for placing country level action across global arena more vocally, strategically with pragmatic approach and with plausible benefits per se).

- Why remain backbench when stakeholders can lead from front and hone their competencies with minimal or almost zero financial and technical assistance from developed economies? As regard to development and adoption of terms of reference, advanced or developed economies are not bound to bear the burden of support for extended period. As per regulatory framework, a foresaid years are lobbied or negotiated for achieving a particular commitment or agreement framework per se. For Conference of Parties, the decision of meeting in an ideal scenario aims for countries devising their own trajectories and pathways so that equity and equality are nudged effectively.

1992 : Establishment of the UNFCCC: Article 6 focuses on education, training, public awareness, public participation, access to information and international cooperation. 1997 : Adoption of the Kyoto Protocol: Article 10(e) contains provisions on education, training, awareness, and capacity-building. 
2001 : COP 7: Launch of two frameworks guiding the implementation of capacitybuilding in developing countries and in countries with economies in transition (2/CP.7; 3/CP.7).

2011: COP17: Launch of the annual Durban Forum on capacity-buildings.

2012 : COP 18: Launch of the eight-year Doha work programme \& annual in-session dialogue on Article 6 of the Convention.

\section{5:}

- COP 21: Adoption of the Paris Agreement: Article 11 on Capacity-building

- Establishment of the Paris Committee on Capacity-building (PCCB)

- Request to establish the Capacity-building Initiative for Transparency

2019:

- COP 25 review of the PCCB and enhance existing institutional arrangements for capacity building.

- CMA 2 decision on initial institutional arrangements for capacity-building under the Paris Agreement

2020: COP 25 : Joint capacity building events to gain momentum in lieu of COVID 19 and recover better.

Gaining momentum in climate change action in collaboration with six members of the PCCB Network (Paris Committee on Capacity-building) - International Centre for Climate Change and Development (ICCCAD), Adaptation Fund. The Climate Group, Climate Chance Association, UNEP-DTU Partnership, and UNDP.

2021: The work of capacity-building network extended to support Climate action implementation. In accordance with UNFCCC extended support for climate action implementation, building capacity to facilitate coherent implementation of Nationally Determined Contributions (NDCs) in the context of national development plans."

\section{A peek through into what's the review on capacity-building needs and gaps : UNFCCC perspective sourcing}

- Capacity gaps and needs of local governments and communities.

- Technical and institutional capacity gaps and needs.

- Capacity gaps of government staff and insufficient institutional capacities.

- Capacity needs related to mainstreaming climate considerations into national planning and budgeting.

- Emergence of new capacity needs, in areas such as implementing nationally determined contributions (NDCs), transparency, REDD-plus and climate finance.

Culpable gaps include lack of coherence and coordination in capacity building and crosscutting issues such as gender responsiveness, human rights, and indigenous peoples' knowledge. 


\section{The decisive requirement :}

- Set timeliness for Climate change Action

- Scope the level of activities

- Extent of climate change support

- Committee on capacity-building

- PCCB activities

- Way forward

The Paris Committee on Capacity-building aims

“... to address gaps and needs, both current and emerging, in implementing capacity-building in developing country Parties and further enhance capacity-building efforts, including with regard to coherence and coordination in capacity-building activities under the Convention."

\section{(1/CP.21, paragraph 71)}

\section{OECD foray into capacity development for climate change action and development}

Developing countries, particularly Least Developed Countries and Small Island Developing States, face very long, costly and arduous processes to access financing. Such processes are often complex, differ across providers of development co-operation, can take too long, and demand resources not present in the poorest and most vulnerable countries. Furthermore, there is a recognition that there are structural issues that go beyond the design of individual funds, for example relating to enabling environments or credit ratings, as well as to the absorptive capacity that countries have once they access finance. While efforts are being made across climate finance channels and providers of development co-operation to access finance for climate change, more needs to be done if we are to collectively achieve the goals enshrined in the Paris Agreement and to promote sustainable development. Capacity development can be a key lever to ensure developing countries can do so. This side-event will focus on some of the challenges and bottlenecks that developing countries and providers of development co-operation face in this area. It will also emphasise current good practices, experiences and examples of success that could inspire replication and scaling-up of approaches to deliver capacity development and that ultimately can help developing countries access much needed climate-related resources. Basic areas of priority include :

- Mobilising finance and investment for the clean energy transition

- Blended Finance Facility for Solar Energy

- Leading efforts towards achievement of zero carbon cities

- Roles of multi-stakeholders towards decarbonization.

Capacity Building Cubicle - What's in store for the stakeholders - Is Climate change action half empty and half full or its a void per se ? time to look out...introspect to act and deliver 
"Capacity-building as per the COP mentioning provides an opportunity for diverse communities of practice across regions to learn from successes, learn from the issues and challenges, share knowledge and best practices, network with one another and enhance the global state of knowledge on capacity-building for climate change".

Capacity building cubicle has - Climate change action digital story telling, climate change action game zone, Beyond classrooms- Climate change action, interactive boot camps, Climate action classrooms and climate change action pocket series on how to implement it. The stakeholders get a niche or platform to interact, work together, upscale and resolve via exchange of knowledge and resource support. The institutional capacities and capabilities is the prime source for the cubicle to deliver outcomes. These include universities, educational organizations, open forums, corporates, sectoral officials, officials aligned for city planning, upkeep and management, industry connect and communities including the citizens them self.

The digital climate action story telling is the most easiest approach of maximising wider outreach by providing a platform as a accelerator, facilitator and incubator. The aim of digital story telling is capacity building development, as on its rests the implementation. It also brings stakeholders to connect themselves firmly as cohorts.

Climate change action game zones are in principal considered as zones for innovation. Skilling and upscaling happen with app based outreaching with games which reflect the real problem in climate action with regard to adaptation, mitigation, assessment and capacitybuilding. They helps to join the dots.

Beyond Classrooms - Climate change action is a actionable and orientable tutoring or mentoring to tackle real problem statement in climate action and not mere learning. These are task based and allows to upscale beyond classroom learning and resolve on the ground problems - emission reduction, how to implement credit savings, how to do trade-offs (please be noted, it includes trade-offs beyond entity or corporate level and includes stakeholders inclusive of citizens), how to mobilize the communities within and beyond the scope of boundaries aligned to - it includes the indigenous people, vulnerable and marginalised including SIDS (Small Island Developing Nations) and LDCs (Least Developing Countries). The economies of transition (EiTs) are not conducive and lack of its support is an hindrance in breakthroughs to happen though solutions are inclusive. Empowering the stakeholders to their problems is what beyond classrooms- climate action is all about. These are inclusive of adaptation plans, mitigation and management of climate complaint policies. Policies fail when they are not brought out beyond classrooms or so to say beyond board and governance machinery, only when they are placed in think tank or thought process of all stakeholders, policies get fruitified and targets are achieved. Beyond classrooms is a superlative mentioning and it includes all the stakeholders i.e.; even citizens. The real problem to policies is implementation - and capacity development action is a solution to it at all the levels of hierarchy.

Interactive boot camps : These cause the ripple effect and such boot camps are a informal way to bring climate change action into development of strong mind set and a sense of responsibility among stakeholders to uphold transparency, ethics and high morals in 
bringing participatory approach and work in cohesion to a problem which is and shall be everyone's and the brunt each of us shall have to bear. It's trickle effect scenario and time is short and impacts are getting added on a continuous basis, so let's tuck in the laces and have a easier approach to resolve this problem via communication, interaction, knowledge transfer, mobilization of the youth and inclusive involvement of entities at all levels. Have boot camps at areas with problem or affected areas rather than in closed enclosures, cabins, boards and institutional settings as areas affected are best self-explanatory with attributes that be discussed, worked upon, consensus be brought in and resolved then and there itself. It's like simplifying the way we communicate to wider stakeholders - and questionnaire are the key attribute of boot camps, as it provides the scope for getting all the requisite information, get the facts checked and give the stakeholders those affected the answers or solutions to negate the impacts. A stakeholder registry is the best example for capacity building action development. Also, important is to give the stakeholders problem and not solution during interactions initiation of boot camps otherwise targets that are set to be achieved cannot be communicated better in their mind-set. Boot camps should be more about perform and deliver, apply and implement, than walk a talk sessions. Let the ripple effect of boot camps have time lines, levels achieved, how many stakeholders meetings and participation happened, how many got benefitted, how many conflicts resolved.

\section{"Climate Change is a reality and not converting solutions to positive impacts is a myth, as emissions piling is happening continuously"}

\section{Can we really achieve net zero is the biggest question?}

How much is emitted ?, if it is absorbed through trajectories, scrubbing and or storage is as simple question for all the bespoke happening on net zero and just transitions. As net zero is emission to storage, then what is done with the storage shall be the next question? If negated and brought will it not cause emission concentration more lethal and per degree rise, as movement is continuous. We are to be more precise with a firm scientific basis backing to what is being mentioned in this paper is - only reducing emissions and equilibrium or stabilisation cannot happen to net zero. Even with applying tools, methodologies, frameworks and research and development including innovation - we cannot go to the preindustrial era, only then net zero will be achieved. Also question that arises is whether net zero is a quantifiable or qualitative commitment per se at the negotiation table? Can we reframe or modify the term "Net Zero" to "Trans Zero" (Transferable Zero) - which can be defined as emission reductions that can be transferred to another emission creating trajectory, resulting in a chain of reduction pathway called as transferable zero. That is a zero being given to a trajectory loaded with higher concentration of emissions for it to sequester it. If net zero is a halt then trans zero is a allocate, transfer, absorb and reduce asset. Trans Zero if introduced in market can be a huge onus for carbon finance, risk assessment and its disclosure. If net zero is a commitment as per the agreement and decision of meetings, then trans zero is transfer capital and whose dividends are not financial gains but reduction in emission uniformly and to be more precise applicative. The aforesaid "Trans Zero" mentioning for introducing in carbon markets and suggestive of replacing net zero is a way through which interactive boot camps will bring in success to implementation and better capacity building action and development. 
Narratives, boot camps and interactive talkathon are way of getting all the information of priority areas of concern, of activities and how stakeholders are responding to it.

\section{"Solutions are writ large in problem itself, tools and framework agreements are just a motivation to advance it into action scientifically"}

Climate apportionment, climate phasing out and climate divestment for fossil fuels are the fundamental attributes, that shall be real potions for Climate action and capacity development.

Climate Classrooms : The science of climate classrooms, is all about innovation, accelerator and co-creation platform. Hands on experience in climate action by way of skill based projects, research and innovation, honing as per problem (action based classrooms). Registry of interactives, and as breakthrough research orientation shall be the climate classrooms key agenda.

Climate change Action Pocket Series : Climate change pocket series is a guiding rule book for all the stakeholders. Which solution is applicable to which part of problem, issue and as per emissions, which tools are to be applied, are given a sequential manner to apply.

As per the UNFCCC, Global Climate Action mentioning in the year book of 2021, in order to mobilize non-party stakeholders into immediate and ambitious action towards achieving a resilient, net-zero future, the Champions launched three campaigns: Race to Zero, rallying non-State actors across the world to halve global emissions by 2030 while unlocking inclusive, sustainable growth; Race to Resilience, aimed at catalyzing a step change in global ambition and action for climate resilience; and the Glasgow Finance Alliance for Net Zero (GFANZ), a global coalition of leading financial institutions that is committed to accelerate and mainstream the decarbonization of the world economy and reach net-zero emissions by 2050. The progress of these campaigns and the increase in non-Party stakeholder participation can be seen as an impetus for enhancing national ambition.

As regard to the latest year book of 2021 mentioning, the following are the global climate action portal, main leads are as follows as per UNFCCC :

\begin{tabular}{|l|}
\hline ASIA-PACIFIC \\
GROUP \\
Cities 372 \\
Regions 23 \\
Companies 1,169 \\
Organizations 179 \\
Investors 185 \\
Countries 56 \\
Total 1,984 \\
\hline
\end{tabular}

\begin{tabular}{|l|}
\hline EASTERN \\
EUROPE GROUP \\
Cities 1,054 \\
Regions 2 \\
Companies 63 \\
Organizations 17 \\
Investors 42 \\
Countries 23 \\
Total 1,201 \\
\hline
\end{tabular}

AFRICAN GROUP
Cities 226
Regions 18
Companies 152
Organizations 107
Investors 34
Countries 54
Total 591

\section{WESTERN EUROPEAN AND OTHERS GROUP}

Cities 8,700

Regions 125

Companies 5,314

Organizations 1,848

Investors 959

Countries 29

Total 16,975 


\section{LATIN AMERICA AND CARIBBEAN GROUP}

Cities 553

Regions 77

Companies 672

Organizations 132

Investors 41

Countries 33

Total 1,508

\section{TOTAL GROUPS}

Cities 10,905

Regions 245

Companies 7,370

Organizations 2,283

Investors 1,261

Countries 195

Total 22,259

\section{A know how on global campaigns for capacity building : Peek - through}

\section{RACE TO ZERO}

The Race to Zero campaign, launched in 2020 under the umbrella of the Climate Ambition Alliance, an initiative set at the 2019 UN Climate Action Summit, rallies on non-State actors across the world to halve global emissions by 2030 while unlocking inclusive, sustainable growth. About 7,800 member from across about 110 countries are now part of the Race, including 67 regions, 1,049 cities, 5,235 businesses,441 financial institutions, 1,039 educational institutions and 52 healthcare institutions (as of November 2021).

In order to ensure that actors are credibly committed to playing their part in the transition to a zero-carbon economy, all participants making commitments under the campaign are required to comply with a minimum set of criteria. These include: (1) Pledge: committing to a high-level pledge to reach net-zero emissions as soon as possible, and setting an interim target reflecting their fair share of halving global $\mathrm{CO}_{2}$ reduction by 2030; (2) Plan: presenting a plan within 12 months of joining, explaining what actions will be taken for achieving both interim and longer-term pledges; (3) Proceed: proceeding towards immediate, meaningful action consistent with the short and long term targets specified; and (4) Publish: reporting on progress against set targets on a public platform on an annual basis.

\section{RACE TO RESILIENCE}

The Race to Resilience, launched at the Climate Adaptation Summit in January 2021, aims at catalyzing a step change in global ambition and action for climate resilience, by mobilizing action from non-Party stakeholders towards building the resilience of four billion people and ensuring that the voices of front-line communities and practitioners are heard. In order to join the campaign, non-State actors are invited to fill in an expression of interest as a partner initiative, committing to (1) taking forward actions that directly contribute to the achievement of the campaign's goal of making four billion people more resilient by 2030; and/or (2) advancing a resilience transformation that will help achieve the campaign's. 


\section{Implementation Lab :}

Capacity building is not just honing core competencies, training, mentoring and awareness but it includes getting together leading figures from national governments, private sector, academia and civil society to discuss about accelerating the industry transition through the establishments, say for example: net zero commitment or setting of NDCs targets. The targets are implementation pointers and its success redefines country's action in their own set criteria and with stakeholder connect.

\section{What has the state of climate action report 2021 got to say in its year book of Global Climate Action :}

* ON TRACK : Change is occurring at or above the pace required to achieve the 2030 target - None

- OFF TRACK: Change is heading in the right direction at a promising, but insufficient pace.

- Share of renewables in electricity generation

- Share of electricity in the industry sector's final energy demand

- Share of electric vehicles in light duty vehicle sales

- Share of battery and fuel cell electric vehicles in bus sales

- Crop yields

- Ruminant meat productivity

- Ruminant meat consumption in the Americas, Europe, and Oceania

- Total public financing for fossil fuels

* WELL OFF TRACK: Change is heading in the right direction, but well below the required pace.

- Share of unabated coal in electricity generation

- Carbon intensity of electricity generation

- Energy intensity of building operations

- Low-carbon steel facilities in operation

- Green hydrogen production

- Share of electric vehicles in the light duty vehicle fleet

- Share of battery and fuel cell electric vehicles in medium- and heavy duty vehicles sales

- Share of low-emissions fuels in the transport sector

- Share of sustainable aviation fuel in global aviation fuel supply

- Share of zero-emissions fuel in international shipping fuel supply

- Rate of technological carbon removal rate

○ Reforestation

- Coastal wetlands restoration

- Total climate finance

- Public climate finance

- Private climate -finance

- Rate of carbon removal from reforestation 
* STAGNANT: Change is stagnating, and a step change in action is needed

- Carbon intensity of global cement production

- Carbon intensity of global steel production

- Share of global emissions covered by a carbon price of at least $\$ 135 / \mathrm{tCO}_{2} \mathrm{e}$

* WRONG DIRECTION: Change is heading in the wrong direction, and a U-turn is needed

- Share of trips made by private light duty vehicles

- Deforestation rate

- Agricultural production GHG emissions

* INSUFFICIENT DATA: Data are insufficient to assess the gap in action required for 2030

$\circ$ Retrofitting rate of buildings

- Carbon intensity of building operations

- Carbon intensity of land-based transport

- Peatlands conversion rate

- Peatlands restoration

- Coastal wetlands conversion rate

- Share of food production lost

- Food waste

- Corporate climate risk disclosure

The biggest gap in climate change action is systemic transformation-addressing the overall framework within which institutions and individuals operate and interact and creating enabling environment through economic and regulatory policies is lacking. What is needed here is systemic level of capacity building.

\section{Nationally Determined Contributions: Fact Check}

Nationally Determined Contributions be further classified to Regionally Determined Contributions and Locally Determined Contributions. Cumulative targets achieved at regional and local scale then should be added to national level contributions, before placing at the global arena for lobbying or negotiations.

\section{Climate Empowerment - Jobs @ Climate change action :}

Empowering the youth as per the market demand, creating enabling environment to foster requisite training and work for issue resolving jobs and aligning learning for availing green collar jobs. What is lacking is requisite skills or expertise and man power, as for climate change action to happen competencies are required at and across all levels including cross cutting issues. To align capacity building to academia and work is what the market demands. With a small yet competent workforce multifaceted issues aligned with climate change action can be resolved.

\section{Policy adherence and Constructive Criticism:}

Having a policy is a but understood attribute once negotiations happen, but adherence needs capacities and capabilities to trickle it to the implementation level and not every policy area 
of activities shall align with the same policy, you cannot expect a 1.5 degrees commitment from an institutional settings, industry, infrastructure, domestic and commercial scoping do

Capacity building core requirement as a part of climate compliance - planning, preparedness and promulgation - for immediate incorporation in climate action development.

not necessarily are bound by 1.5 degrees commitment. Here the capacity building approach shall be demand or need driven, competent them as per their requirement as we are doing with country specific commitments. Constructive criticism is a gap driven motivation to bombard stakeholders to collaborate more, interact more and contribute more (CIC). Through externalities explanatories, mobilizing the stakeholders is the real purpose of this critique.

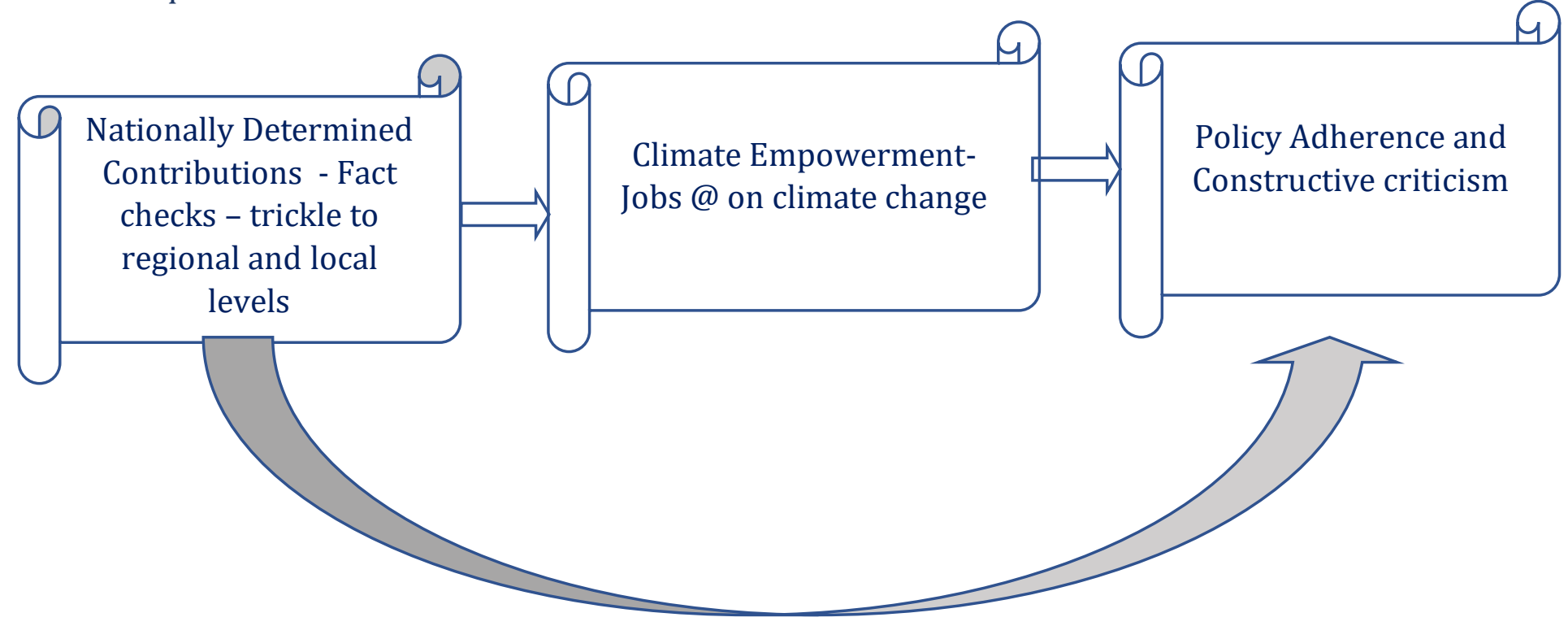

Capacity building core requirement as a part of climate compliance - planning, preparedness and promulgation - for immediate incorporation in climate action development.

\section{Climate Emergency - Why there is a need for all the countries to call for climate emergencies?}

Advanced countries like New Zealand, Norway, Netherlands including many European Union countries have declared climate emergency including few of the small island developing countries as a preparedness measure and as a part of future proofing exercise of capacity development. It is not necessary and imperative to wait for climate disasters to strike and then operational measures are taken including management. Climate emergencies are disaster preparedness tools and nudgers. 
"Why wait when we can negate"

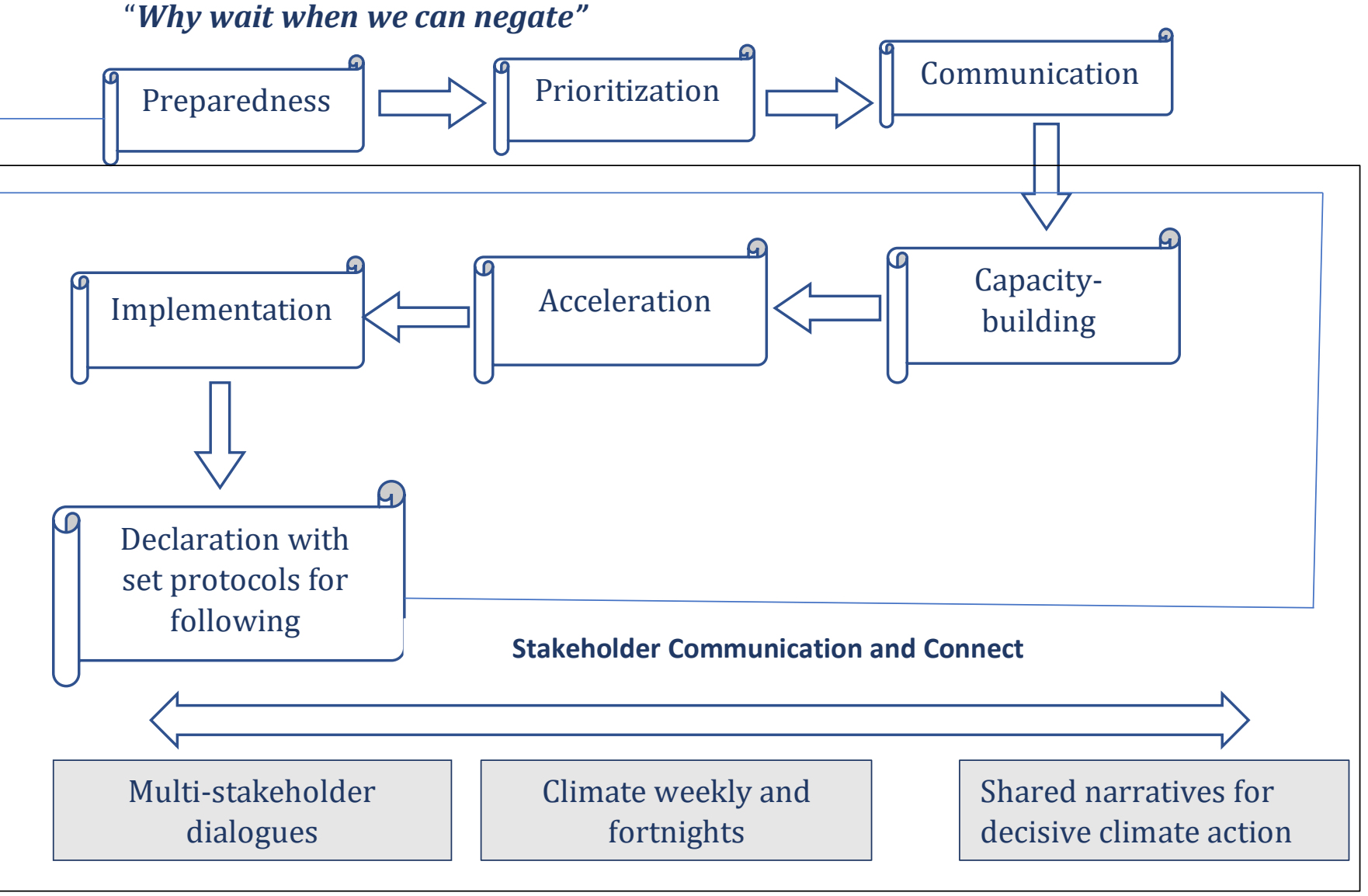

\section{Way Forward:}

$\checkmark$ Implement trans zero on an immediate basis and make it policy inclusive for implementation

$\checkmark$ Let's communicate, collaborate and cocreate - stakeholder participatory approach.

$\checkmark$ Open ended forums with multi-stakeholders dialogues and narratives.

$\checkmark$ Policies implementation to be aligned with capacity-building and stringent regulations.

\section{"Let's be the torch bearers for global climate action"! Let's do it.....}

\section{References}

1. UNFCCC www.https://unfccc.int/

2. OECD https://www.oecd.org/about/

3. GCF https://www.greenclimate.fund/

4. Nationally Determined Contributions https://www.un.org/en/climatechange/allabout-ndcs 